\title{
General medical practitioners' knowledge and management of oral and dental
}

\section{problems}

\author{
Elissa Biniecki, Caitlyn Foote, Grace Gilbert, and Paul Abbott
}

UWA Dental School, The University of Western Australia, Nedlands, Australia

\section{RESEARCH}

Please cite this paper as: Biniecki E, Foote C, Gilbert G, Abbott P. General medical practitioners' knowledge and management of oral and dental problems. AMJ 2018;11(7):390-396.

https://doi.org/10.21767/AMJ.2018.3471

\section{Corresponding Author:}

Winthrop Prof. Paul Abbott AO

UWA Dental School

The University of Western Australia

17 Monash Avenue

NEDLANDS WA 6009 Australia

Tel: +61 864577665

Email: paul.v.abbott@uwa.edu.au

\section{ABSTRACT}

\section{Background}

Many patients with oral and dental problems seek help from medical practitioners rather than from dentists. Little is known about why this occurs in Australia and how medical practitioners manage these problems.

\section{Aims}

The aims were to: 1 ) provide insight into why patients seek treatment for oral and dental problems from medical practitioners, 2) assess how these patients were managed by medical practitioners, and 3) assess medical practitioners' perception of their knowledge of oral and dental problems.

\section{Methods}

An electronically distributed survey was completed by general medical practitioners who were members of the Australian Medical Association in Western Australia. The survey had 19 questions with a combination of both quantitative and qualitative responses. All responses were anonymous.

\section{Results}

From 130 responses, the most common reasons for patients to present with dental-related issues to general medical practitioners included: cost of dental consults, perceived need for antibiotics, ease of access and immediate relief of pain. Respondents reported that 68 per cent of presentations were during typical business hours. Antibiotic (83 per cent) and analgesic (91 per cent) prescriptions followed by referral to dentists (76 per cent) were the most frequently reported managements. About half the respondents felt their knowledge of oral and dental problems was adequate while 35 per cent felt it was inadequate and 16 per cent felt it was deficient in some areas.

\section{Conclusion}

Patients present to medical practitioners mainly for pain relief or antibiotic prescription. Most practitioners manage these cases with antibiotic and analgesic prescriptions. Practitioners' knowledge of dental-related problems varies with about half feeling it could be improved.

\section{Key Words}

Dental problems, analgesics, antibiotics

\section{What this study adds:}

\section{What is known about this subject?}

Little is known about why and when many patients with oral and dental problems present to medical practitioners rather than to dentists in Australia.

\section{What new information is offered in this study?}

Typically patients present during office hours for antibiotics, ease of access and immediate relief of pain. Most practitioners prescribe antibiotics and analgesics for these patients. 
3. What are the implications for research, policy, or practice?

Many medical practitioners feel their knowledge is deficient yet they still prescribe antibiotics which are usually not required. Education and better referral processes are needed.

\section{Background}

Lack of education regarding oral and dental diseases amongst medical practitioners during their formal education has frequently been cited in the literature. ${ }^{1-3}$ Despite this, general medical practitioners are often the first point of call for patients with oral and dental problems. ${ }^{2,4,5}$ The number of toothaches presenting at emergency medical clinics has become increasingly common, especially in minority groups and low socioeconomic individuals. ${ }^{6}$ These findings strengthen the need for medical practitioners to be well educated in appropriate triage and management of dental problems.

Providing timely and effective treatment greatly increases patient comfort and the overall prognosis. Despite this, medical practitioners' management of dental problems is usually limited to pain relief and/or antibiotic prescription without referral. ${ }^{7,8}$ The literature indicates that patients who present to medical practitioners are less likely to receive appropriate surgical (i.e., dental) intervention and are more likely to be prescribed antibiotics. ${ }^{9}$ According to Anderson et al., 68 per cent of patients seen by medical practitioners with dental-related issues received antibiotics compared to 28 per cent of those seen by dentists. ${ }^{10}$ Cope et al. found that many medical practitioners considered antibiotics to be the first-line treatment for acute dentalrelated issues. ${ }^{9}$ However, the use of antibiotics usually does not address the cause of the presenting complaint. ${ }^{6}$ Moreover, with increasing antimicrobial resistance being reported globally, prescribing antibiotics for conditions which do not necessitate them is of major concern ${ }^{9,11}$ and all practitioners should take responsibility to avoid using antibiotics whenever possible.

The frequency with which patients present with dentalrelated problems to general medical practices is scarcely reported. Estimates range from approximately once a week to once every few months. Variances in these frequencies have been attributed to disruption of local dental services, more rigorous triaging, lack of after-hours availability of dentists, improved dental access, costs, lack of insurance, no regular dentist, dental anxiety and better education. ${ }^{2,4,7,9,12}$ However, these reports are primarily of European and American origin, highlighting the gap in comparable baseline trends in Australian general medical practices. The National Health and Hospitals Reform Commission published a report in 2009 for the Australian Government which showed that approximately 650,000 Australians are on public dental waiting lists with only 45 per cent of Australians having private health insurance. ${ }^{13}$ Coupled with a lack of general dental cover under the Medicare Benefits Scheme and strict inclusion criteria for the various Commonwealth-supported dental subsidy schemes, the cost of dental treatment may be a driving factor for patients who seek dental-related treatment at Australian medical practices. ${ }^{8,10}$

Overall, the incidence and management of dental-related problems at general medical practices within Australia are unknown. Investigation of this would provide noteworthy insight as to why patients seek medical rather than dental assistance.

The aims of this study were to provide insight into the motives contributing to patients seeking dental-related treatment through general medical practitioners and to assess how these patients were routinely managed by the practitioners. A further aim was to assess the perception of medical practitioners regarding their knowledge of oral and dental problems.

\section{Method}

This study consisted of a survey which was approved by the University of Western Australia's Human Research Ethics Committee. The survey was conducted at the UWA Dental School at The University of Western Australia with assistance from the Australian Medical Association (AMA) between June 2016 and June 2017. All general medical practitioners who were members of the AMA at that time were invited to participate. The survey was distributed by all State and Territory Branches of the AMA to their members via email and/or through their newsletters. This sampling technique was employed in order to maximise the numbers and demographic spectrum of participants. Potential participants received an invitation to participate and an information page which detailed the aims and requirements of the survey.

In order to obtain information from a broad array of general medical practitioners nationally, collection of data was conducted through a standardised, electronically distributed survey. It comprised nineteen questions, both qualitative and quantitative in nature, which were designed using Qualtrics Survey software (Qualtrics, Provo, UT). The survey was voluntary and consent was provided through following 
the hyperlink to the designated webpage. Information collected via the survey encompassed basic demographic parameters (e.g., remoteness, state where practising) and sample specifics (e.g., medical education, specialisation, years in practice). Questions were also asked about the frequency, timing and management of patients presenting with dental-related problems to general medical practices. Participants had six months to complete the survey with reminders sent after one and three months. The questionnaire was anonymous and no identifiable information was requested.

Data was extracted from survey software and used to generate baseline frequencies and graphs. Correlation analysis was completed via SPSS Statistics software.

\section{Results}

Although the survey was distributed to members of the Australian Medical Association nationally, 92.9 per cent of the respondents were from Western Australia (WA). Due to the poor response rate from the other States, all nonWestern Australian responses were excluded from the analysis. Of the 130 respondents from WA, 67 (52 per cent) were males and 63 (48 per cent) were females. The number of years practicing as a general medical practitioner ranged from 1 to 54 years with a mean of 24.6 years. The majority of respondents (52.3 per cent) practiced in major cities (RA1), followed by 21.5 per cent in inner regional areas (RA2), and 11.5 per cent in very remote (RA5) areas. Twothirds (67 per cent) worked in private practice, 14.3 per cent in the public sector and 18.6 per cent worked in both private and public sectors.

Forty percent of respondents reported that the majority of their knowledge of dental-related conditions came from their original medical degree followed by private study $(22.3$ per cent), interaction with dental colleagues (16.9 per cent), CPD (7 per cent), specialty training (7 per cent), from their own personal dental experiences ( 5 per cent) and formal professional training (1.5 per cent). Only 49.2 per cent felt that their understanding of dental-related conditions was at least adequate while 34.6 per cent felt their knowledge was poor and 16.2 per cent felt it was deficient in certain areas (Table 1). Table 2 summarises the particular topics where respondents felt they could improve their knowledge.

Respondents reported that the majority (67.7 per cent) of patients presenting with dental-related issues attended during typical business hours with only 10 per cent presenting after normal hours on weekdays and 5.7 per cent on weekends after midday on Saturday. Almost all (99.2 per cent) of the patients were adults.

According to the respondents, there were many reasons why patients presented to general medical practitioners with dental-related issues (Table 3 ). The most common included cost of dental treatment (80.8 per cent), ease of access to medical practitioners compared to dentists $(68.5$ per cent), perceived need for antibiotics (60 per cent) and seeking immediate pain relief ( 50 per cent). Participants reported that the most expected patient outcomes of the appointment were the prescription of antibiotics (83.1 per cent) and pain relief medications (78.5 per cent) with 20 per cent expecting a medical certificate only and 5.4 per cent expecting referral to a dentist.

Antibiotic and analgesic prescriptions followed by referral to a dentist were the most frequently reported managements by the medical practitioners for dental-related issues and especially to manage pain (Table 4). Eighty percent of participants routinely prescribed antibiotics for dentalrelated pain management. The types of analgesics and antibiotics prescribed by the practitioners are presented in Tables 5 and 6. Dental abscesses (94.6 per cent), facial swellings (83.1 per cent) and severe toothaches (48.5 per cent) were the most commonly reported indications for antibiotic prescription. Most (76.1 per cent) participants would routinely refer to the patient to a dentist for treatment.

\section{Discussion}

This study is the first to assess the motives contributing to patients seeking treatment by medical practitioners for dental-related problems and to assess how these patients were routinely managed by these practitioners in WA specifically.

The survey was distributed via the various state AMA branches to a potential 7,356 members of the AMA. ${ }^{14}$ Hence, there was a low response rate but the reasons for this are unknown. Although 140 responses were received, only ten (7 per cent) were from states other than WA. Since the number of responses from WA comprised a significant portion of the total data (93 per cent), non-Western Australian responses were excluded from the analysis. Consequently, the final sample comprised 130 of a possible 3,534 registered WA general medical practitioners, according to the Department of Health General Practice Statistics 2015-2016. ${ }^{15}$ This sample set was reflective of the WA general medical practitioner population with a slight minority of respondents (48.1 per cent) being females - but 
this is similar to the current number of female (43.8 per cent) general practitioners in WA. The respondents were also representative of all Remoteness Areas within WA with the ratio of responses being similar to the statistics published by the Australian Department of Health in $2006 .{ }^{16}$

It was hypothesised that the time of dental patient presentation to general medical practices would typically be outside standard dental clinic opening hours due to lack of access to dentists. This was based on a qualitative study of 17 general medical practitioners which reported that the frequency of dental consultations varied from approximately once a week to once every few months. ${ }^{9}$ Increases in these figures were attributed to disruption of local dental services whilst decreases were attributed to improved dental access and better education of patients concerning where to seek appropriate dental care. However, no Australian studies were found to support this hypothesis. Furthermore, the responses of this survey suggest the contrary with the majority (67.7 per cent) of patients presenting during typical business hours which were defined as Monday-Friday 8.00am-5.00pm and Saturday 8.00am-12.00noon. Some respondents (16.9 per cent) reported no difference regarding the time of day and only 9.2 per cent and 6.2 per cent reported that patients presented outside typical business hours and on weekends, respectively.

Previous studies have reported the main reasons for patients attending medical practices with dental issues included the lack of after-hours availability, geographic location, cost, lack of insurance, no regular dentist and dental anxiety/fear. ${ }^{1-4,7}$ Results of this survey are consistent with these studies, with the cost of dental treatment (14.1 per cent) and ease of access ( 12 per cent) being the most common reasons reported by respondents when asked about their perceptions of dental-related attendances at their clinics.

Patients' perceived need for antibiotics (10.5 per cent) was a frequently recorded reason for attendance of patients with dental problems at medical clinics although this has not been previously reported in the literature. Interestingly, antibiotic prescription was the most popular management employed (43 per cent) by the practitioners in this survey. This suggests a perception by medical practitioners that patients expect an antibiotic prescription upon presentation at their clinic and consequently, antibiotics are a common management strategy for the majority of the dental-related presentations.
It is well documented that there is increasing concern regarding antimicrobial resistance to antibiotics, especially when prescribed for circumstances that do not require them. The respondents identified the most common conditions requiring systemic antibiotic prescription to be a dental abscess (34.1 per cent) followed by facial swelling (29.9 per cent), severe toothache (17.4 per cent) and pain following tooth extraction (8.6 per cent). However dental infections are always best managed by surgical (i.e., dental) intervention by a dentist rather than antibiotic prescription. ${ }^{17}$ In addition, many oral and dental pain conditions do not require antibiotics at all, and particularly if the appropriate dental treatment has been provided. This was reflected in a study by Anderson et al. who found that patients presenting to medical practitioners are less likely to receive surgical (i.e., dental) intervention and they are more likely to be prescribed antibiotics. ${ }^{18}$ Cope et al. also found many general medical practitioners considered antibiotics to be the first-line treatment for acute dental-related issues. $^{9}$

The trends from medical practitioners in this study show that broad spectrum antibiotics were preferred for treating dental-related problems. Amoxicillin with clavulanic acid (37.1 per cent) was the most prescribed antibiotic followed by amoxicillin (28.6 per cent) and metronidazole (20.5 per cent). Contradictory to this study's findings, the literature shows medical practitioners in emergency settings often prefer to treat dental pain with narrow spectrum antibiotics such as phenoxymethylpenicillin (37.5 per cent) and phenoxymethylpenicillin plus metronidazole (18.8 per cent). ${ }^{19}$ In accordance with this, Anderson et al. found that medical practitioners were more likely to prescribe broadspectrum antibiotics (61 per cent) compared to dental practitioners (49 per cent). ${ }^{18}$

Despite general practitioners often being the first "point of call" for patients with dental concerns, many medical practitioners graduate from university with limited knowledge about the management of dental issues. ${ }^{1-3}$ Comments made by medical practitioners in this study acknowledged the lack of dental training in their medical degrees. Despite this, many participants (40 per cent) stated that they gained most of their dental-related knowledge during their original medical degree. The literature contradicts this with the general consensus suggesting that medical practitioners receive little to no dental education during their medical training. A survey in the UK ${ }^{1}$ found 11 of 21 medical schools incorporated only some oral pathology into their teaching and a study by Abu-Dawoud et al. ${ }^{3}$ reported that a substantial 96.6 per cent of medical 
practitioners had received no dental education during their training. Interestingly, only 49.2 per cent of the participants in this study felt that their dental knowledge was at least adequate. This may be a significant factor when assessing the appropriateness of treatment provided by medical practitioners for dental-related issues. Limited formal training may cause treatment options to be limited. Consequently, pain relief and antibiotic prescription without referral to a dentist was frequently cited as the management strategy. ${ }^{12,18}$

Similar to antibiotic prescriptions, prescription of pain relief medications was both a frequently expected (by the patient) and the prescribed treatment option both in the literature $^{9}$ and in this study. A significant portion of practitioners in this study (89.2 per cent) reported routinely prescribing pain-relief medication as part of their dental pain management. Paracetamol with codeine, paracetamol alone, and ibuprofen were the most commonly prescribed. According to Therapeutic Guidelines Oral and Dental, these medications are appropriate for relief of most dental pain ${ }^{20}$ with non-steroidal anti-inflammatory drugs considered to be the most effective choice for blocking dental pain due to their peripheral action in reducing inflammation as well as reducing pain. ${ }^{21}$ Codeine is advised to be reserved for severe or post-operative pain. ${ }^{20}$ However, Therapeutic Guidelines also emphasise that pain relief medications should be used in conjunction with appropriate dental treatment rather than just being used alone. Interestingly, several participants reported that they administered a "dental block" (that is, an inferior alveolar nerve block injection of a local anaesthetic solution) as a method of pain relief.

Limitations of this study include the method of distribution of the survey and the low response rate. As the survey was distributed via email databases, the sample was limited to those who were members of the AMA and who actively used their email address. Due to the poor number of responses from most Australian States, the survey was limited to responses from WA. This resulted in a smaller sample size than expected when considering the number of medical practitioners in Australia, as well as when restricted to WA. Comparable and current literature in this area is scarce; therefore this research should be considered as a pilot study to assess Australian trends. Further research is required to analyse and quantify medical practitioners' knowledge, diagnostic accuracy and management of dental and oral problems.

\section{Conclusion}

Patients present to medical practitioners mainly for pain relief or prescription of antibiotics. Most practitioners manage these cases with antibiotics and analgesics which are often inappropriate in the absence of appropriate dental treatment. Medical practitioners' knowledge of oral and dental-related problems varies with about half of the respondents stating that their knowledge could be improved

\section{References}

1. McCann PJ, Sweeney MP, Gibson J, et al. Training in oral disease, diagnosis and treatment for medical students and doctors in the United Kingdom. Br J Oral Maxillofac Surg. 2005;43:61-64. doi: 10.1016/j.bjoms.2004.08.023

2. Abbott PV. Medical management of dental and oral pain. Aust Prescr. 2007;30:77-79. doi: 10.18773/austprescr.2007.044

3. Abu-Dawoud M, Al-Enezi B, Andersson L. Knowledge of emergency management of avulsed teeth among young physicians and dentists. Dent Traumatol. 2007;23:348355. doi: 10.1111/j.1600-9657.2006.00477.x

4. Anderson R, Richmond DW, Thomas S. Patient presentation at medical practices with dental problems: An analysis of the 1996 General Practice Morbidity Database for Wales. Br Dent J. 1999;186:297-300. doi:10.1038/sj.bdj.4800091

5. Kingon A. Solving dental problems in general practice. Aust Fam Physician. 2009;38:211-216. PMID: 19350070

6. Lee $\mathrm{HH}$, Lewis $\mathrm{CW}$, McKinney CM. Disparities in emergency department pain treatment for toothache. JDR Clin Translat Res. 2016;1:226-233. doi: 10.1177/2380084416655745

7. Mansour $\mathrm{MH}$, Cox SC. Patients presenting to the general practitioner with pain of dental origin. Med J Aust. 2006;185:64-67. PMID: 16842057

8. Australian Government Department of Health. Report on the Third Review of the Dental Benefits Act 2008 2016

https://www.health.gov.au/internet/main/publishing.ns f/Content/5AE86FB9D21A8277CA257BF0001F952F/\$File /Report\%20on\%20the\%20Third\%20Review\%20of\%20th e\%20Dental\%20Benefits\%20Act\%202008\%20(D16150740).PDF (accessed April 2018).

9. Cope AL, Wood F, Francis NA, et al. General practitioners' attitudes towards the management of dental conditions and use of antibiotics in these consultations: a qualitative study. BMJ Open. 2015;5:e008551. doi: 10.1136/bmjopen-2015-008551

10. Beech N, Goh R, Lynham A. Management of dental infections by medical practitioners. Aust Fam Physician. 2014;43:289-291. PMID: 24791770 
11. Ventola CL. The antibiotic resistance crisis: part 1: causes and threats. P\&T. 2015;40:277-283. PMCID: PMC4378521

12. Skapetis T, Gerzina T, Hu W. Management of dental emergencies by medical practitioners: Recommendations for Australian education and training. Emerg Med Australas. 2011;23:142-152. doi: 10.1111/j.1742-6723.2011.01384.x

13. Australian Government National Health and Hospitals Reform Commission. A Healthier Future for All Australians - Final Report of the National Health and Hospitals Reform Commission. 2009. http://www.cotasa.org.au/cms_resources/documents/n ews/nhhrc_report.pdf (accessed April 2018).

14. Australian Medical Association Annual Report 2016. https://ama.com.au/sites/default/files/annualreport/AMA_Annual_Report_2016.pdf (accessed April 2018).

15. Australian Government Department of Health. General Practice Statistics

2015-2016. http://health.gov.au/internet/main/publishing.nsf/Cont ent/General+Practice+Statistics-1 (accessed April 2018).

16. Australian Government Department of Health. Report on the Audit of Health Workforce in Rural and Regional Australia.

2008. http://www.health.gov.au/internet/publications/publish ing.nsf/Content/work-res-ruraud-toc (accessed April 2018).

18. Dar-Odeh NS, Abu-Hammad OA, Al-Omiri MK, et al. Antibiotic prescribing practices by dentists: a review. Ther Clin Risk Manag. 2010;6:301-306. PMCID: PMC2909496

19. Anderson R, Calder L, Thomas D. Antibiotic prescribing for dental conditions: general medical practitioners and dentists compared. $\mathrm{Br}$ Dent J. 2000;188:398-400. doi:10.1038/sj.bdj.4800493

20. Pennycook A, Makower R, Brewer A, et al. The management of dental problems presenting to an accident and emergency department. J Roy Soc Med. 1993;86:702-703. PMC1294360

21. Therapeutic Guidelines. Therapeutic Guidelines Oral and Dental Version 2. Melbourne: Therapeutic Guidelines Limited. 2012;127-136.

\section{ACKNOWLEDGEMENTS}

The authors gratefully acknowledge the UWA Dental School for supporting this project. The authors would also like to thank all General Medical Practitioners that participated in the study and the various State and Territory Branches of the Australian Medical Association for assistance in disseminating the survey invitation to participants.

\section{PEER REVIEW}

Not commissioned. Externally peer reviewed.

\section{CONFLICTS OF INTEREST}

The authors declare that they have no competing interests.

\section{FUNDING}

Not applicable

\section{ETHICS COMMITTEE APPROVAL}

The University of Western Australia's Human Research Ethics Committee - Approval No. RA/4/1/8504

Table 1: General medical practitioners' perception of their adequacy of dental-related knowledge

\begin{tabular}{|l|c|}
\hline Level of Knowledge & Percentage (\%) \\
\hline Excellent & 3.9 \\
\hline Adequate & 45.4 \\
\hline Poor & 34.6 \\
\hline Deficient in certain areas & 16.2 \\
\hline
\end{tabular}

Table 2: Topics where respondents believe their knowledge could improve

\begin{tabular}{|l|l|}
\hline Topic & $\begin{array}{l}\text { Percentage } \\
\text { (\%) }\end{array}$ \\
\hline Dental and orofacial trauma & $15.46 \%$ \\
\hline Acute oral and dental infections & $12.45 \%$ \\
\hline Chronic oral and dental infections & $18.07 \%$ \\
\hline Paediatric dentistry and oral conditions & $15.66 \%$ \\
\hline Oral malignant and premalignant lesions & $15.66 \%$ \\
\hline Dental prosthetic related conditions & $13.45 \%$ \\
\hline $\begin{array}{l}\text { Identifying when a patient requires } \\
\text { referral to a dentist }\end{array}$ & $9.24 \%$ \\
\hline
\end{tabular}

Table 3: General medical practitioners' perceptions of the reasons why patients attend their practices with dentalrelated problems

\begin{tabular}{|l|l|}
\hline Reason for attendance & $\begin{array}{l}\text { Percentage } \\
\text { (\%) }\end{array}$ \\
\hline Cost of consult & $14.13 \%$ \\
\hline Cost of medication & $2.56 \%$ \\
\hline Perceived need for antibiotics & $10.50 \%$ \\
\hline $\begin{array}{l}\text { Demographics/location/greater } \\
\text { accessibility }\end{array}$ & $5.25 \%$ \\
\hline Shortage of dental services & $5.52 \%$ \\
\hline $\begin{array}{l}\text { Ease of access to a medical } \\
\text { practitioner compared to a dentist }\end{array}$ & $11.98 \%$ \\
\hline
\end{tabular}




\begin{tabular}{|l|l|}
\hline After hours/time of day & $4.31 \%$ \\
\hline Dental anxiety & $4.44 \%$ \\
\hline Dissatisfaction with past dental care & $0.81 \%$ \\
\hline Immediate relief of pain & $8.75 \%$ \\
\hline Drug/medication prescription & $5.92 \%$ \\
\hline Lack of private health insurance & $7.67 \%$ \\
\hline $\begin{array}{l}\text { Lack of understanding of the } \\
\text { presenting complaint }\end{array}$ & $6.33 \%$ \\
\hline $\begin{array}{l}\text { Referred or poorly differentiated } \\
\text { complaint }\end{array}$ & $3.90 \%$ \\
\hline $\begin{array}{l}\text { Patient unaware of available dental } \\
\text { services }\end{array}$ & $2.42 \%$ \\
\hline $\begin{array}{l}\text { Presenting concurrently with a } \\
\text { medical problem }\end{array}$ & $5.52 \%$ \\
\hline
\end{tabular}

Table 6: Choice of antibiotics prescribed by respondents for dental-related problems

\begin{tabular}{|l|l|}
\hline Drug & Percentage (\%) \\
\hline Penicillin V & 6.2 \\
\hline Amoxicillin & 28.6 \\
\hline Amoxicillin + Clavulanic Acid & 37.1 \\
\hline Metronidazole & 20.5 \\
\hline Tetracycline & 1 \\
\hline Erythromycin & 3.3 \\
\hline Other & 3.3 \\
\hline
\end{tabular}

Table 4: Dental-related conditions where general practitioners perceive a need for an antibiotic prescription

\begin{tabular}{|l|l|}
\hline Condition & $\begin{array}{l}\text { Percentage } \\
\text { (\%) }\end{array}$ \\
\hline Dull toothache & $4.16 \%$ \\
\hline Severe toothache & $17.45 \%$ \\
\hline $\begin{array}{l}\text { Sensitivity to hot/cold } \\
\text { foods/drinks }\end{array}$ & $2.77 \%$ \\
\hline Facial Swelling & $29.92 \%$ \\
\hline Abscess & $34.07 \%$ \\
\hline $\begin{array}{l}\text { Pain following recent tooth } \\
\text { extraction }\end{array}$ & $8.59 \%$ \\
\hline $\begin{array}{l}\text { Tooth avulsion (“knocked-out } \\
\text { tooth”) }\end{array}$ & $0.83 \%$ \\
\hline Patient asks for a prescription & $2.22 \%$ \\
\hline
\end{tabular}

Table 5: Choice of analgesic medications prescribed by respondents for relief of dental pain

\begin{tabular}{|l|l|}
\hline Drug & Percentage (\%) \\
\hline Paracetamol & 23.6 \\
\hline Paracetamol + Codeine & 29.6 \\
\hline Ibuprofen & 27.7 \\
\hline Ibuprofen + Codeine & 6.3 \\
\hline Other NSAIDs & 7.4 \\
\hline Opioid-based analgesics & 2.5 \\
\hline Other & 3.2 \\
\hline
\end{tabular}

